\title{
Microgeographic genetic variation in the haploid and diploid stages of the moss Polytrichum juniperinum Hedw.
}

\author{
David J. Innes
}

Department of Biology, Memorial University of Newfoundland, St. John's, Newfoundland, A1B 3X9, Canada.

Electrophoretic variability at six enzyme loci was used to examine genotypic variation in the haploid (gametophyte) and diploid (sporophyte) stages of the moss Polytrichum juniperinum Hedw. from a population in eastern Newfoundland. Samples from 16 sites revealed 13 six-locus haploid genotypes and a total of 18 gametophyte genotypes (ten male and eight female) when the genotypic data were combined with sex. Gametophyte genotypic diversity was low within each site and there was marked microgeographic differentiation between sites within the population. There was, however, no relationship between genetic and microgeographic distances among the sites. The observed number of six-locus genotypes and their relative frequency within the population did not differ significantly from the values expected for a sexually reproducing population. This genotypic structure is consistent with sexual reproduction generating the observed variation but vegatative reproduction and limited dispersal maintaining microgeographic genetic heterogeneity within the population. Diploid, six-locus genotypes were determined for 137 sporophytes. The sporophyte genotypic variation suggested that mating was occurring predominantly between female and male gametophytes within the same site. Fewer gametophyte genotypes were observed than were expected to be produced by sporophyte genotypes observed at each site, suggesting that genetical and/or ecological factors may be limiting the recruitment of new haploid gametophyte genotypes into the population.

\section{INTRODUCTION}

The life-cycle of most higher plant and animal species is dominated by the diploid phase while the haploid phase is usually only present in the form of gametes, or strongly reduced, predominantly endophytic gametophytes. The widespread occurrence of a dominant diploid phase has been considered as evidence for the adaptive significance of diploidy and several theories have been proposed to explain the adaptive advantage of diploidy over haploidy. For example, diploids can generate more genetic variation due to heterozygosity, acquire adaptive mutations twice as fast as haploids and can mask the expression of recessive deleterious mutations (Paquin and Adams, 1983; Bernstein et al., 1987; Bell, 1988).

In contrast, there have been fewer arguments presented for the advantages of haploidy. Paquin and Adams (1983) and Lewis (1985) suggested an ecological rather than genetical explanation in which haploidy was less costly than diploidy and would therefore be favoured under conditions of nutrient (e.g., nitrogen and phosphorus) limitation.
Few generalizations can be made about the relative advantages and disadvantages of haploidy because much less is known about the evolutionary genetics of haploid compared with diploid organisms. For example, most of the information on genetic variation in natural populations has been for organisms with a dominant diploid phase. Many groups of organisms (algae, mosses, liverworts, ferns, fungi) have a life-cycle with varying degrees of dominance and persistence of the haploid phase, but few of these species have been investigated for genetic variation in natural populations.

Mosses and liverworts (bryophytes) have a lifecycle in which the haploid stage dominates (see Newton, 1984 and Wyatt, Odrzykoski and Stonebuner, 1989 for a discussion on haploidy and polyploidy in moss gametophytes), often forming large mats by vegetative growth (Longton and Schuster, 1983). In dioecious species a gametophyte is either male or female with probably a chromosomal sex-determining mechanism (Ramsay and Berrie, 1982). Fertilisation of archegonia on female gametophytes depends on sperm transfer via water from adjacent antheridia on male 
gametophytes. In Polytrichum the antheridia are clustered in splash cups and rain drops splash the sperm out. After fertilisation the zygote grows into a diploid sporophyte which remains attached to the female gametophyte. Meiosis takes place in the distal sporangium of the sporophyte and the released spores germinate, giving rise to haploid male and female gametophytes. Both the fertilisation mechanism and restricted spore dispersal limit potential gene flow with estimates ranging from only $5-50 \mathrm{~cm}$ (gamete dispersal) to $1-2 \mathrm{~m}$ (spore dispersal), depending on the species (Anderson and Lemmon, 1974; Reynolds, 1980; Anderson and Snider, 1982; Wyatt, 1977; 1982). Much of the information on the potential for gamete and spore dispersal has been summarized in detail by Longton (1976), Wyatt (1982), van Zanten and Pocs (1981), Longton and Schuster (1983), Wyatt and Anderson (1984) and Wyatt (1985).

Recent studies on selected moss and liverwort species (Krzakowa and Szweykowski, 1979; Cummins and Wyatt, 1981; Yamazaki, 1981; 1984; Daniels, 1982; Vries et al., 1983; Zielinski, 1984; Wyatt, 1985; Shaw, Meagher and Harley, 1987; Hofman, 1988; Wyatt, Odrzykoski and Stoneburner, 1989; Wyatt, Stoneburner and Odrzykoski, 1989) suggest that the presence of a dominant haploid stage has not resulted in reduced genetic variation compared to diploid organisms, at least as measured by allozyme variation. These studies document the presence of genetic variation both within and between populations of haploid gametophytes. However, there have been few attempts to use genetic markers to combine information on the reproductive biology and genetic structure of bryophyte species (Zielinski, 1986). This is especially important because the mode of reproduction can have a strong influence on the level and organization of genetic variation within and between populations. Many moss species appear to lack sporophytes and only reproduce asexually (Longton, 1976; Longton and Schuster, 1983). Even for species known to reproduce sexually, there is no information on the relative importance of gametophytes added to the population by asexual reproduction of the existing genotypes compared to new gametophyte genotypes added by sexual reproduction (Longton, 1976; Wyatt, 1982; Longton and Schuster, 1983; Mishler, 1988).

The present study examined allozymic variation in a population of the moss species Polytrichum juniperinum, which is known to produce sporophytes. Multilocus genotypic variation provided information on the relative influence of vege- tative and sexual reproduction on genotypic diversity and the extent of microgeographic differentiation. Sexual reproduction in the population was studied by comparing genetic variation among male and female gametophytes and the sporophyte associated with each female gametophyte. The results show a moderate level of genotypic diversity, but despite frequent sporophyte production there appears to be limited recruitment of new genotypes into the population.

\section{MATERIALS AND METHODS}

\section{Collection and electrophoresis}

Samples were collected during April of 1988 and 1989 from an approximately $200 \mathrm{~m}^{2}$ area near Logy Bay, Newfoundland $\left(47^{\circ} 38^{\prime} \mathrm{N}, 52^{\circ} 40^{\prime} \mathrm{W}\right)$. Sixteen sites within this area (fig. 1) were identified by numbered flags and individual plants selected from within about a $10 \mathrm{~cm}$ radius of the marker. Single shoots of male gametophytes and female gametophytes with developing sporophytes were collected from each site (sample sizes in table 1), except for five sites (A1, D, K2, L, C2) in which male gametophytes were not observed. Non-reproductive gametophytes were not collected.

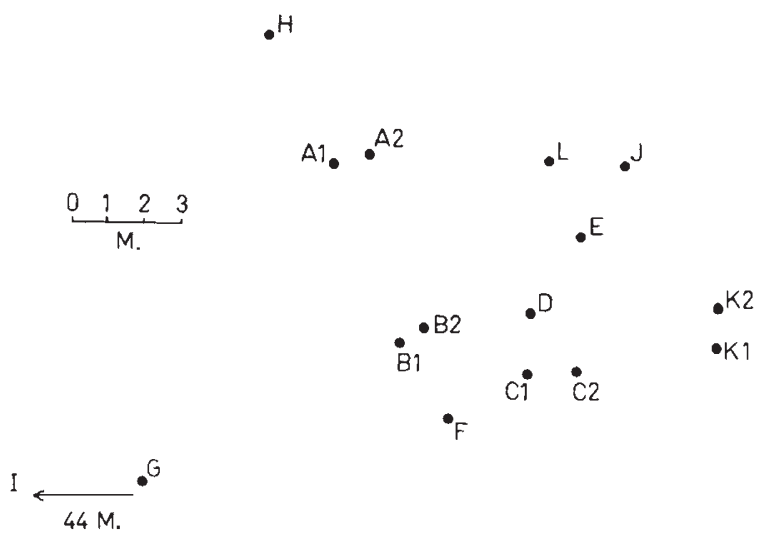

Figure 1 Locations of the 16 sites of Polytrichum juniperinum sampled from near Logy Bay, Newfoundland.

Samples were stored in plastic bags at $5^{\circ} \mathrm{C}$ for no longer than three weeks. Tissue from the three life-history stages (haploid male and female gametophytes and the diploid sporophyte) was prepared for electrophoresis by grinding in a few drops of $p \mathrm{H} 8.0$ buffer prepared as described by Shaw et al. (1987). Cellulose acetate electrophoresis (Helena Laboratories, Beaumont, Texas) 
Table 1 Sample sizes for the male and female gametophytes and diploid sporophytes $(2 N)$ for Polytrichum juniperinum collected in 1988 and 1989 from 16 sites

\begin{tabular}{|c|c|c|c|c|c|c|c|}
\hline \multirow[b]{3}{*}{ Site } & \multicolumn{7}{|c|}{ Sample sizes } \\
\hline & \multicolumn{3}{|c|}{1988} & \multicolumn{3}{|c|}{1989} & \multirow[b]{2}{*}{ Total } \\
\hline & $\delta$ & $q$ & $2 N$ & $\delta$ & $q$ & $2 N$ & \\
\hline Al & - & 4 & 4 & - & 5 & 5 & 18 \\
\hline A2 & 3 & 3 & 3 & 5 & 5 & 5 & 24 \\
\hline $\mathrm{B} 1$ & 3 & 3 & 3 & 5 & 5 & 5 & 24 \\
\hline $\mathrm{B} 2$ & 4 & 4 & 4 & 5 & 5 & 5 & 27 \\
\hline $\mathrm{C} 1$ & 5 & 5 & 5 & 5 & 5 & 5 & 30 \\
\hline $\mathrm{C} 2$ & - & 5 & 1 & - & 5 & 5 & 16 \\
\hline D & - & 5 & 5 & - & 10 & 10 & 30 \\
\hline $\mathrm{E}$ & 3 & 3 & 3 & 5 & 5 & 5 & 24 \\
\hline $\mathrm{F}$ & 6 & 6 & 6 & 5 & 5 & 5 & 33 \\
\hline $\mathrm{G}$ & 7 & 7 & 7 & 5 & 5 & 5 & 36 \\
\hline $\mathrm{H}$ & 4 & 4 & 2 & 5 & 5 & 5 & 25 \\
\hline I & 4 & 4 & 4 & 5 & 5 & 5 & 27 \\
\hline $\mathbf{J}$ & 3 & 3 & 3 & 5 & 5 & 5 & 24 \\
\hline K1 & 3 & 0 & 0 & 5 & 4 & 4 & 16 \\
\hline $\mathrm{K} 2$ & - & 3 & 1 & - & 5 & 5 & 14 \\
\hline $\mathrm{L}$ & - & 3 & 2 & - & 5 & 5 & 15 \\
\hline Totals & 45 & 62 & 53 & 55 & 84 & 84 & 383 \\
\hline
\end{tabular}

was carried out using a $p \mathrm{H} 8.5$ Tris-glycine buffer $(3 \mathrm{~g} /$ litre Trizma Base, $14.4 \mathrm{~g} /$ litre glycine) and each sample assayed for five enzymes; PGI (phosphoglucose isomerase), PGM (phosphoglucomutase), GOT (glutamate oxaloacetate transaminase), AMY (amylase) and ADH (alcohol dehydrogenase). These enzymes were chosen because they showed consistent resolution. Staining methods followed Harris and Hopkinson (1976). Information from polymorphic enzyme loci enabled the identification of genetically distinct gametophytes by combining the six-locus genotype data with sex.

\section{Microgeographic differentiation}

Microgeographic pattern in genetic differentiation was tested in two ways. First, genetic distance was compared with the geographic distance among all possible pairs of the 16 sites. Calculation of genetic distance was based on presence/absence data for the gametophyte genotypes observed among pairs of sites in the population. A matrix of genetic distances among the 16 sites was calculated as the complement of the Jaccard similarity measure, $S_{J}$ (Sneath and Sokal, 1973). A rank correlation was then computed for the genetic and geographic distances among the 120 site pairs.

A second approach for measuring microgeographic genetic differentiation was to compare the genetic similarity among the six-locus gametophyte genotypes occurring at the same site and then test if these were on average more similar than a random sample of gametophyte genotypes from all sites. Genetic similarity among all possible pairs of genotypes was measured as the proportion of alleles shared across all six polymorphic loci.

\section{Genotypic diversity}

Haploid genotypic diversity was determined by enumerating the unique gametophyte genotypes observed at each site. Due to vegetative growth, multiple gametophyte samples within a site would probably represent clones of the same genotype and gametophyte genotype frequency would therefore be biased by variation in sample size among sites. This was avoided by only counting individuals within a site which were genetically distinct based on their six-locus genotype and sex. This approach resulted in a sample size of 33 individuals which was used to calculate allele frequencies for the individual loci within the population. Although not large, this sample size has been found to be adequate for estimating allele frequency variation in populations of other moss species (Wyatt et al., 1988; Wyatt, Odrzykoski and Stoneburner, 1989). Genotypic variation in the population was quantified by the total number of different six-locus genotypes observed as well as a measure of genotypic diversity. Observed genotypic diversity was calculated as $G=1 / \sum_{i=1}^{k} g_{i}^{2}$ where $g_{i}$ is the frequency of the $i$ th six-locus genotype for the $k$ six-locus genotypes observed in the population (Stoddard, 1983). Expected values of genotypic diversity and number of sixlocus genotypes for an equivalent sexually reproducing population with the same allele frequencies were generated using a repeated sampling process (Hoffmann, 1986; Innes et al., 1986). A random number generator produced 100 samples of haploid six-locus genotypes using the observed allele frequencies and assuming free recombination among the loci. The mean genotypic diversity and mean number of six-locus genotypes were then compared with the observed values using a $t$-test for comparing a single observation with a sample mean (Sokal and Rohlf, 1981; Hoffmann, 1986; Innes et al., 1986).

\section{Sporophyte genotypic diversity}

Six-locus genotypes were determined for each sporophyte to provide information on mating within the population. The genotype of the male 
parent was easily inferred because the sporophyte remains attached to the female gametophyte. The observed sporophyte six-locus genotypes were also used to generate the expected gametophyte types which would develop from spores, assuming random association among the loci and between the loci and sex.

\section{RESULTS}

\section{Electrophoretic variation}

Eight putative gene loci were resolved; Pgi-1 (most cathodal), Pgi-2, Pgi-3 (most anodal), Pgm, Got-1 (most cathodal), Got-2 (most anodal), Amy and $A d h$. All were polymorphic except $P g i-2$ and $A d h$ (see below). This variation appeared to be genetically based. Only single bands were observed for gametophytes as would be expected for haploid tissue. Homozygous and heterozygous patterns were observed for sporophytes as would be expected for diploid tissue. Furthermore, alleles found in the maternal tissue were always present in the tissue of the attached sporophyte. Identical banding patterns were observed in 1988 and 1989 except for the Amy locus where the slow allele (S) scored in 1988 was resolved into two alleles ( $\mathrm{S}$ and $\mathrm{M}$ ) in 1989 samples. A single occurrence of a very slow allele (V) at this locus was observed in the 1989 samples. In addition, a second Got locus (Got-1) was resolved in 1989. Utilizing information from all loci, samples from 1988 were combined with the 1989 samples except where the multilocus genotypes were ambiguous. For example, a single 1988 sporophyte heterozygous for $A d h$ was eliminated from the data set due to ambiguities concerning its genotype at Amy and Got-1.

\section{Gametophyte genotypic diversity}

Thirteen haploid genotypes were observed based on the six polymorphic loci. Five of the 13 were associated with both male and female gametophytes, five with only male gametophytes and three with only female gametophytes (table 2). A total of 18 (ten male and eight female) gametophyte genotypes (table 2) were observed in the sample of 246 individual gametophyte shoots from all sites (table 3).

Gametophyte genotypic diversity was low within each site (table 3 ) and there was no relationship (Spearman's rank correlation $r_{\mathrm{s}}=0.33, P=$ 0.22 ) between sample size and the number of gametophyte genotypes detected. Of the five sites in which only female gametophytes were observed,
Table 2 Observed Polytrichum juniperinum gametophyte genotypes $(\mathrm{F}=$ female, $\mathrm{M}=$ male $)$ based on six polymorphic loci (Pgi-1, Pgm, Pgi-3, Amy, Got-2, Got-1)

\begin{tabular}{|c|c|c|c|c|c|c|}
\hline \multirow{2}{*}{$\begin{array}{l}\text { Gametophyte } \\
\text { genotype } \\
1 \mathrm{M}\end{array}$} & \multicolumn{6}{|c|}{ Six-locus genotype* } \\
\hline & $\mathbf{M}$ & M & $\mathrm{F}$ & $\mathbf{M}$ & $\mathrm{F}$ & $\mathrm{F}$ \\
\hline $1 \mathrm{~F}$ & $\mathbf{M}$ & $\mathbf{M}$ & $\mathrm{F}$ & $\mathbf{M}$ & $\mathrm{F}$ & $\mathrm{F}$ \\
\hline $2 \mathrm{M}$ & $\mathbf{M}$ & $\mathbf{M}$ & $S$ & $\mathrm{M}$ & $\mathrm{F}$ & $\mathrm{F}$ \\
\hline $2 \mathrm{~F}$ & M & M & $\mathbf{S}$ & $\mathbf{M}$ & $\mathrm{F}$ & $\mathrm{F}$ \\
\hline $3 \mathrm{M}$ & M & $\mathrm{S}$ & $\mathrm{F}$ & $\mathrm{S}$ & $\mathrm{F}$ & $\mathrm{F}$ \\
\hline $3 \mathrm{~F}$ & M & $\mathrm{S}$ & $\mathrm{F}$ & $\mathbf{S}$ & $\mathrm{F}$ & $\mathrm{F}$ \\
\hline $4 \mathrm{M}$ & $\mathbf{M}$ & $\mathrm{S}$ & $\mathbf{S}$ & $\mathbf{S}$ & $\mathrm{F}$ & $\mathrm{F}$ \\
\hline $4 \mathrm{~F}$ & $\mathbf{M}$ & S & $\mathrm{S}$ & $\mathrm{S}$ & $\mathrm{F}$ & $\mathrm{F}$ \\
\hline $5 \mathrm{M}$ & $\mathbf{M}$ & S & $\mathbf{S}$ & S & S & $\mathrm{F}$ \\
\hline $5 \mathrm{~F}$ & $\mathbf{M}$ & $S$ & $\mathrm{~S}$ & $S$ & S & $\mathrm{F}$ \\
\hline $6 \mathrm{M}$ & $\mathbf{M}$ & $\mathrm{F}$ & $\mathrm{F}$ & $\mathrm{F}$ & $\mathrm{F}$ & $\mathrm{F}$ \\
\hline $7 \mathrm{M}$ & $\mathrm{F}$ & M & $\mathrm{F}$ & $\mathbf{M}$ & $\mathrm{F}$ & $\mathrm{F}$ \\
\hline $8 \mathrm{M}$ & $\mathrm{F}$ & $\mathbf{M}$ & $\mathrm{F}$ & $\mathrm{S}$ & F & $\mathrm{F}$ \\
\hline $9 \mathrm{M}$ & $\mathbf{M}$ & $S$ & $\mathrm{~S}$ & $\mathbf{M}$ & $\mathrm{F}$ & $\mathrm{F}$ \\
\hline $10 \mathrm{M}$ & $\mathbf{M}$ & $\mathbf{S}$ & $\mathrm{S}$ & $\mathbf{M}$ & $\mathrm{F}$ & $S$ \\
\hline $11 \mathrm{~F}$ & $\mathbf{M}$ & $\mathrm{S}$ & $\mathrm{F}$ & $\mathbf{M}$ & $\mathrm{F}$ & $F$ \\
\hline $12 \mathrm{~F}$ & $\mathbf{M}$ & $S$ & $\mathrm{~S}$ & V & S & $\mathrm{F}$ \\
\hline $13 \mathrm{~F}$ & $\mathrm{~S}$ & $\mathbf{S}$ & $\mathrm{F}$ & $\mathbf{M}$ & $\mathrm{F}$ & $\mathrm{F}$ \\
\hline
\end{tabular}

* Allele designations: $\mathrm{V}=$ very slow, $\mathrm{S}=$ slow, $\mathrm{M}=$ medium, $\mathrm{F}=$ fast.

two sites (A1, C2) consisted of only a single gametophyte genotype and three sites $(\mathrm{D}, \mathrm{K} 2, \mathrm{~L})$ consisted of two different gametophyte genotypes. Of the remaining 11 sites with both male and female gametophytes, most (A2, B1, C1, E, F, G, $\mathrm{I}, \mathrm{J})$ consisted of only a single male and a single female gametophyte genotype (table 3 ). The remaining three sites (B2, H, K1) were each composed of three gametophyte genotypes (table 3 ).

The distribution of the male gametophyte genotypes among the 16 sites appeared to be more restricted than the female gametophyte genotypes. Nine of the ten male gametophyte genotypes were only found at single sites and only one (9M) was found at three different sites (table 3 ). Four $(1 \mathrm{~F}, 5 \mathrm{~F}, 12 \mathrm{~F}, 13 \mathrm{~F})$ of the eight female gametophyte genotypes were found at single sites and genotypes $2 \mathrm{~F}, 3 \mathrm{~F}, 4 \mathrm{~F}$ and $11 \mathrm{~F}$ were found at two, four, six and five sites, respectively (table 3 ).

\section{Microgeographic differentiation}

Four pairs of sites (A1-A2, B1-B2, C1-C2, K1-K2) were separated by about $1 \mathrm{~m}$ (fig. 1) and shared at least one gametophyte genotype (table 3 ). However, many of the sites were genetically distinct regardless of their geographic relationship 
Table 3 Numbers of the 18 gametophyte genotypes of Polytrichum juniperinum for 16 sites

\begin{tabular}{|c|c|c|c|c|c|c|c|c|c|c|c|c|c|c|c|c|c|c|c|}
\hline \multirow[b]{2}{*}{ Site } & \multirow[b]{2}{*}{$N$} & \multicolumn{18}{|c|}{ Gametophyte genotype } \\
\hline & & $1 \mathrm{M}$ & $1 \mathrm{~F}$ & $2 \mathrm{M}$ & $2 \mathrm{~F}$ & $3 \mathrm{M}$ & $3 \mathrm{~F}$ & $4 \mathrm{M}$ & $4 \mathrm{~F}$ & $5 \mathrm{M}$ & $5 \mathrm{~F}$ & $6 \mathrm{M}$ & $7 \mathrm{M}$ & $8 \mathrm{M}$ & $9 \mathrm{M}$ & $10 \mathrm{M}$ & $11 \mathrm{~F}$ & $12 \mathrm{~F}$ & $13 \mathrm{~F}$ \\
\hline $\mathrm{Al}$ & 9 & & & & & & 9 & & & & & & & & & & & & \\
\hline $\mathrm{A} 2$ & 16 & & & & & & 8 & & & & & & & & 8 & & & & \\
\hline B1 & 16 & & & & & & & & 8 & 8 & & & & & & & & & \\
\hline B2 & 18 & & & & & & & & 4 & & & & & & 9 & & 5 & & \\
\hline $\mathrm{Cl}$ & 20 & & & & & & & & 10 & & & 10 & & & & & & & \\
\hline $\mathrm{C} 2$ & 10 & & & & & & & & 10 & & & & & & & & & & \\
\hline D & 15 & & & & & & & & & & & & & & & & 2 & & 13 \\
\hline $\mathrm{E}$ & 16 & & & & & & & & & & & & & & & 8 & 8 & & \\
\hline $\mathrm{F}$ & 22 & & & 11 & & & 11 & & & & & & & & & & & & \\
\hline G & 24 & & & & & & & & & & & & 12 & & & & 12 & & \\
\hline $\mathbf{H}$ & 18 & & & & & & & 8 & & & & & & & 1 & & 9 & & \\
\hline I & 18 & 9 & & & & & 9 & & & & & & & & & & & & \\
\hline $\mathrm{J}$ & 16 & & & & & & & & & & 8 & & & 8 & & & & & \\
\hline K1 & 12 & & & & 1 & 8 & & & 3 & & & & & & & & & & \\
\hline $\mathrm{K} 2$ & 8 & & & & 1 & & & & 7 & & & & & & & & & & \\
\hline $\mathrm{L}$ & 8 & & 7 & & & & & & & & & & & & & & & 1 & \\
\hline Totals & 246 & 9 & 7 & 11 & 2 & 8 & 37 & 8 & 42 & 8 & 8 & 10 & 12 & 8 & 18 & 8 & 36 & 1 & 13 \\
\hline
\end{tabular}

$N=$ number of gametophyte shoots sampled at each site.

and there was no significant (Spearman's rank correlation $\left.\quad r_{\mathrm{s}}=0 \cdot 16, \quad P=0.09\right) \quad$ association between genetic distance and geographic distance among the 16 sites (fig. 1, table 3, table 4).

Genetic similarity among the 13 six-locus genotypes fell into five categories. The most similar genotypes shared alleles at five of the six loci and the least similar shared an allele at only one locus (table 2). The observed number of each of the five similarity values between genotypes occurring at the same site was compared to the number expec- ted based on the frequency of each similarity category in the matrix of similarity values among all 13 genotypes. Genotypes occurring at the same site were found to be no more similar $\left(\chi^{2}=6 \cdot 37\right.$, $\mathrm{df}=4, P>0.05)$ than genotypes compared from any site.

\section{Genotypic diversity}

Allele frequencies (table 5) for the six polymorphic loci were calculated from the relative occurrence

Table 4 Geographic distance in metres (above diagonal) and genetic distance (below diagonal) for the 16 sites of Polytrichum juniperinum

\begin{tabular}{|c|c|c|c|c|c|c|c|c|c|c|c|c|c|c|c|c|}
\hline & \multicolumn{16}{|c|}{ Sample site } \\
\hline & $\mathrm{Al}$ & $\mathrm{A} 2$ & B1 & $\mathrm{B} 2$ & $\mathrm{C} 1$ & $\mathrm{C} 2$ & $\mathrm{D}$ & $\mathrm{E}$ & $\mathrm{F}$ & $\mathrm{G}$ & $\mathbf{H}$ & I & $\mathbf{J}$ & $\mathrm{K} 1$ & $\mathrm{~K} 2$ & $\mathrm{~L}$ \\
\hline $\mathrm{Al}$ & & 0.92 & $5 \cdot 22$ & $5 \cdot 10$ & $7 \cdot 78$ & $8 \cdot 58$ & $6 \cdot 64$ & 6.90 & $7 \cdot 56$ & $10 \cdot 14$ & 3.98 & $49 \cdot 96$ & $7 \cdot 80$ & $11 \cdot 54$ & $11 \cdot 11$ & $5 \cdot 80$ \\
\hline $\mathrm{A} 2$ & 0.50 & & $5 \cdot 18$ & 4.93 & $7 \cdot 36$ & $8 \cdot 06$ & 6.08 & $6 \cdot 11$ & $7 \cdot 43$ & $10 \cdot 79$ & $4 \cdot 33$ & $50 \cdot 88$ & 6.90 & $10 \cdot 83$ & $10 \cdot 35$ & 4.90 \\
\hline B1 & $1 \cdot 00$ & $1 \cdot 00$ & & 0.72 & $3 \cdot 59$ & $4 \cdot 75$ & $3 \cdot 61$ & $5 \cdot 61$ & $2 \cdot 39$ & $7 \cdot 96$ & $9 \cdot 18$ & $51 \cdot 14$ & $7 \cdot 75$ & $8 \cdot 60$ & $8 \cdot 66$ & $6 \cdot 40$ \\
\hline $\mathrm{B} 2$ & $1 \cdot 00$ & 0.75 & 0.75 & & $3 \cdot 14$ & $4 \cdot 24$ & $2 \cdot 94$ & $4 \cdot 89$ & $2 \cdot 50$ & 8.68 & $9 \cdot 08$ & $51 \cdot 77$ & 7.03 & $8 \cdot 02$ & $8 \cdot 02$ & $5 \cdot 72$ \\
\hline $\mathrm{C} 1$ & 1.00 & $1 \cdot 00$ & 0.67 & 0.75 & & $1 \cdot 20$ & $1 \cdot 70$ & 3.92 & $2 \cdot 51$ & $10 \cdot 92$ & 11.68 & $54 \cdot 58$ & $6 \cdot 22$ & $5 \cdot 15$ & $5 \cdot 41$ & $5 \cdot 82$ \\
\hline $\mathrm{C} 2$ & 1.00 & $1 \cdot 00$ & 0.50 & 0.67 & 0.50 & & $2 \cdot 00$ & $3 \cdot 60$ & $3 \cdot 64$ & $21 \cdot 10$ & $12 \cdot 38$ & $55 \cdot 79$ & $5 \cdot 75$ & 3.95 & $4 \cdot 25$ & $5 \cdot 74$ \\
\hline $\mathrm{D}$ & 1.00 & $1 \cdot 00$ & $1 \cdot 00$ & 0.75 & 1.00 & 1.00 & & $2 \cdot 39$ & $3 \cdot 64$ & $11 \cdot 50$ & $10 \cdot 40$ & $54 \cdot 70$ & $4 \cdot 72$ & $5 \cdot 20$ & $5 \cdot 10$ & $4 \cdot 13$ \\
\hline $\mathrm{E}$ & 1.00 & 1.00 & $1 \cdot 00$ & 0.75 & $1 \cdot 00$ & 1.00 & 0.67 & & 6.02 & $13 \cdot 57$ & $10 \cdot 12$ & $56 \cdot 20$ & $2 \cdot 33$ & $4 \cdot 84$ & $4 \cdot 25$ & $2 \cdot 25$ \\
\hline $\mathrm{F}$ & 0.50 & 0.67 & $1 \cdot 00$ & 1.00 & $1 \cdot 00$ & 1.00 & 1.00 & 1.00 & & 8.49 & $11 \cdot 54$ & $52 \cdot 33$ & $8 \cdot 35$ & $7 \cdot 54$ & $7 \cdot 89$ & $7 \cdot 50$ \\
\hline G & 1.00 & 1.00 & $1 \cdot 00$ & 0.75 & $1 \cdot 00$ & $1 \cdot 00$ & 0.67 & 0.67 & 1.00 & & $12 \cdot 64$ & $44 \cdot 00$ & $15 \cdot 64$ & $16 \cdot 03$ & $16 \cdot 32$ & 14.09 \\
\hline $\mathrm{H}$ & 1.00 & 0.75 & 1.00 & 0.50 & $1 \cdot 00$ & $1 \cdot 00$ & 0.75 & 0.75 & 1.00 & 0.75 & & $48 \cdot 85$ & $10 \cdot 31$ & $14 \cdot 95$ & $14 \cdot 35$ & 8.42 \\
\hline I & 0.50 & 0.67 & 1.00 & $1 \cdot 00$ & 1.00 & $1 \cdot 00$ & 1.00 & $1 \cdot 00$ & 0.67 & $1 \cdot 00$ & $1 \cdot 00$ & & 57.66 & $59 \cdot 71$ & $59 \cdot 79$ & $55 \cdot 70$ \\
\hline $\mathbf{J}$ & 1.00 & $1 \cdot 00$ & $1 \cdot 00$ & 1.00 & 1.00 & 1.00 & 1.00 & $1 \cdot 00$ & $1 \cdot 00$ & $1 \cdot 00$ & $1 \cdot 00$ & 1.00 & & $5 \cdot 64$ & 4.69 & $2 \cdot 00$ \\
\hline K1 & 1.00 & $1 \cdot 00$ & 0.75 & $0 \cdot 80$ & 0.75 & 0.67 & 1.00 & 1.00 & 1.00 & 1.00 & $1 \cdot 00$ & 1.00 & $1 \cdot 00$ & & $1 \cdot 10$ & $6 \cdot 87$ \\
\hline K2 & 1.00 & $1 \cdot 00$ & 0.67 & 0.75 & 0.67 & 0.50 & 1.00 & $1 \cdot 00$ & $1 \cdot 00$ & 1.00 & 1.00 & $1 \cdot 00$ & 1.00 & 0.33 & & $6 \cdot 10$ \\
\hline L & $1 \cdot 00$ & 1.00 & $1 \cdot 00$ & 1.00 & 1.00 & 1.00 & 1.00 & $1 \cdot 00$ & 1.00 & 1.00 & $1 \cdot 00$ & $1 \cdot 00$ & 1.00 & $1 \cdot 00$ & $1 \cdot 00$ & \\
\hline
\end{tabular}


Table 5 Allele frequencies for six polymorphic loci for the Logy Bay population of Polytrichum juniperinum. Sample size $(N=33)$ based on the sum of the site occurrences for the six-locus genotypes listed in table 2

\begin{tabular}{lllllll}
\hline \multicolumn{7}{c}{ Locus } \\
\cline { 2 - 7 } Allele & Pgi-1 & Pgm & Pgi-3 & Amy & Got-2 & Got-1 \\
\hline V & - & - & - & 0.03 & - & - \\
S & 0.03 & 0.76 & 0.52 & 0.46 & 0.09 & 0.03 \\
M & 0.91 & 0.21 & - & 0.49 & - & - \\
F & 0.06 & 0.03 & 0.48 & 0.03 & 0.91 & 0.97 \\
\hline
\end{tabular}

of the 18 gametophyte genotypes among the sites (table 3). Almost identical allele frequency values were obtained based on the total sample of 246 gametophytes. Calculated allele frequencies were used to generate expected frequencies of the sixlocus haploid genotypes. Thirteen six-locus genotypes were observed and the observed genotypic diversity was $8 \cdot 30$. These values did not differ significantly $(t=0 \cdot 28, \mathrm{df}=99, P>0.05$ and $t=0.17 \mathrm{df}=99, P>0.05$, respectively) from the average number of six-locus genotypes $(14 \cdot 56, \mathrm{sd}$ $2 \cdot 36)$ or the average genotypic diversity $(8 \cdot 83$, sd $1 \cdot 77$ ) for 100 simulated samples of size 33 sampled from a population with the same allele frequencies and assuming sexual reproduction and random association among loci.

\section{Sporophyte genotypic diversity and matings}

Diploid six-locus genotypes were determined for the sample of 137 sporophytes collected from the 16 sites (table 6). Fifteen of the 16 sites had only one or two sporophyte genotypes. Site D (table 6) had four different sporophyte genotypes (two of the five matings produced the same sporophyte genotype). The genotype of the female parent of each sporophyte is known and the six-locus genotype of the male parent can therefore be inferred. Only two of the 137 matings (both at site D) involved a single male genotype that was not one of the ten male gametophyte genotypes previously observed in the population (table 6). Both sexes were sampled at eleven of the sites. In all but one $(4 \mathrm{~F} \times 3 \mathrm{M}$ at site $\mathrm{C} 1)$ of 94 matings, the putative male parental gametophyte was present at the same site as the female parent (table 3 and table 6). The inferred male genotype $(3 \mathrm{M})$ for the mating at site $\mathrm{C} 1$ was also observed more than $5 \mathrm{~m}$ away at site K1.

Five of the sites had females with a developing sporophyte but no observable male gametophytes within about a $10 \mathrm{~cm}$ radius. At three of these sites $(\mathrm{A} 1, \mathrm{C} 2, \mathrm{~L})$, males with the required genotype were observed at adjacent sites (A2, C1, J) all within 1 or $2 \mathrm{~m}$ or less (fig. 1, table 4 ). Male genotypes for two of the matings $(13 \mathrm{~F} \times 9 \mathrm{M} ; 13 \mathrm{~F} \times 10 \mathrm{M})$ at site $\mathrm{D}$ were observed within $3 \mathrm{~m}$ at nearby sites $\mathrm{B} 2$ and

Table 6 Sporophyte genotypes of Polytrichum juniperinum observed and the postulated male gametophyte genotypes mated to produce each diploid genotype

\begin{tabular}{|c|c|c|c|c|c|c|c|}
\hline Mating & $P g i-1$ & $P g m$ & $P g i-3$ & $A m y$ & Got-2 & Got-1 & Sites (N) \\
\hline $3 \mathrm{~F} \times 9 \mathrm{M}$ & $\mathrm{MM}$ & SS & FS & SM & $\mathrm{FF}$ & FF & $\mathrm{A} 1(9), \mathrm{A} 2(8)$ \\
\hline $4 \mathrm{~F} \times 5 \mathrm{M}$ & $\mathrm{MM}$ & SS & SS & SS & FS & FF & $\mathrm{B} 1(8)$ \\
\hline $4 \mathrm{~F} \times 9 \mathrm{M}$ & $\mathrm{MM}$ & SS & SS & SM & FF & FF & $\mathrm{B} 2(4)$ \\
\hline $11 \mathrm{~F} \times 9 \mathrm{M}$ & $\mathrm{MM}$ & SS & FS & MM & FF & FF & $\mathrm{B} 2(5), \mathrm{H}(1)$ \\
\hline $4 \mathrm{~F} \times 6 \mathrm{M}$ & $\mathrm{MM}$ & SF & SF & $\mathrm{SF}$ & FF & FF & $\mathrm{C} 1(9), \mathrm{C} 2(6)$ \\
\hline $4 \mathrm{~F} \times 3 \mathrm{M}$ & $\mathrm{MM}$ & SS & SF & SS & FF & FF & $\mathrm{C} 1(1), \mathrm{K} 1(3)$ \\
\hline $13 \mathrm{~F} \times 9 \mathrm{M}$ & SM & SS & FS & $\mathrm{MM}$ & FF & FF & $\mathrm{D}(1)$ \\
\hline $11 \mathrm{~F} \times ?$ & MS & SS & FS & $\mathrm{MM}$ & FF & FS & $\mathrm{D}(2)$ \\
\hline $13 \mathrm{~F} \times 10 \mathrm{M}$ & SM & SS & FS & $\mathrm{MM}$ & FF & FS & $\mathrm{D}(6)$ \\
\hline $13 \mathrm{~F} \times 3 \mathrm{M}$ & SM & SS & FF & MS & FF & $\mathrm{FF}$ & $\mathrm{D}(4)$ \\
\hline $13 \mathrm{~F} \times 2 \mathrm{M}$ & $\mathrm{SM}$ & SM & FS & $\mathrm{MM}$ & FF & $\mathrm{FF}$ & $\mathrm{D}(2)$ \\
\hline $11 \mathrm{~F} \times 10 \mathrm{M}$ & $\mathrm{MM}$ & SS & FS & $\mathrm{MM}$ & FF & FS & $E(8)$ \\
\hline $3 \mathrm{~F} \times 2 \mathrm{M}$ & $\mathrm{MM}$ & SM & FS & SM & FF & FF & $F(11)$ \\
\hline $11 \mathrm{~F} \times 7 \mathrm{M}$ & $\mathrm{MF}$ & SM & FF & $\mathrm{MM}$ & FF & FF & $\mathrm{G}(12)$ \\
\hline $11 \mathrm{~F} \times 4 \mathrm{M}$ & $\mathrm{MM}$ & SS & FS & MS & FF & FF & $\mathrm{H}(6)$ \\
\hline $3 \mathrm{~F} \times 1 \mathrm{M}$ & $\mathrm{MM}$ & SM & FF & SM & FF & FF & $\mathrm{I}(9)$ \\
\hline $5 \mathrm{~F} \times 8 \mathrm{M}$ & $\mathrm{MF}$ & SM & SF & SS & SF & FF & $\mathrm{J}(8)$ \\
\hline $2 \mathrm{~F} \times 3 \mathrm{M}$ & $\mathrm{MM}$ & MS & SF & MS & FF & FF & $\mathrm{K} 1(1)$ \\
\hline $4 \mathrm{~F} \times 2 \mathrm{M}$ & $\mathrm{MM}$ & $\mathrm{SM}$ & SS & $\mathrm{SM}$ & FF & $\mathrm{FF}$ & $\mathrm{K} 2(5)$ \\
\hline $2 \mathrm{~F} \times 1 \mathrm{M}$ & $\mathrm{MM}$ & $\mathrm{MM}$ & SF & $\mathrm{MM}$ & FF & $\mathrm{FF}$ & $\mathrm{K} 2(1)$ \\
\hline $1 \mathrm{~F} \times 8 \mathrm{M}$ & $\mathrm{MF}$ & $\mathrm{MM}$ & $\mathrm{FF}$ & MS & FF & FF & $\mathrm{L}(6)$ \\
\hline $12 \mathrm{~F} \times 8 \mathrm{M}$ & $\mathrm{MF}$ & $\mathrm{SM}$ & SF & VS & SF & FF & $\mathrm{L}(1)$ \\
\hline
\end{tabular}

$N=$ number of sporophytes samples at each site and ?= male genotype not observed in the population. 
E. The appropriate males for the remaining four types of matings (site $\mathrm{D}: 13 \mathrm{~F} \times 2 \mathrm{M}, 13 \mathrm{~F} \times 3 \mathrm{M}$; site $\mathrm{K} 2: 4 \mathrm{~F} \times 2 \mathrm{M}, 2 \mathrm{~F} \times 1 \mathrm{M})$ were found at distant sites with other male gametophytes in between and probably do not reflect the true location of the male parents.

All sites showed fewer gametophyte genotypes than expected based on the observed genotype of the sporophytes at each site and assuming random association among the six loci and sex (table 7). In many cases the expected gametophyte genotypes for any one site were not observed at any of the sites sampled in the population. Diploid sporophytes at sites $J$ and $L$ had a higher heterozygosity (table 6) and consequently a larger number of expected gametophyte genotypes, many of which were not observed at any of the sites (table 7).

Table 7 Observed and expected number of Polytrichum juniperinum gametophyte genotypes for the 16 sites. Expected number of gametophyte genotypes based on the sporophyte genotypes observed at each site (table 6)

\begin{tabular}{llll} 
& \multicolumn{2}{l}{ Gametophyte genotypic diversity } \\
\cline { 2 - 4 } & & & $\begin{array}{l}\text { Not observed } \\
\text { at any site }\end{array}$ \\
\hline Site & Observed & Expected & 2 \\
A2 & 1 & 8 & 2 \\
B1 & 2 & 8 & 0 \\
B2 & 2 & 4 & 2 \\
C1 & 3 & 6 & 11 \\
C2 & 2 & 16 & 11 \\
D & 1 & 16 & 18 \\
E & 2 & 28 & 5 \\
F & 2 & 8 & 6 \\
G & 2 & 16 & 4 \\
H & 2 & 8 & 2 \\
I & 3 & 8 & 3 \\
J & 2 & 8 & 25 \\
K1 & 2 & 32 & 6 \\
K2 & 3 & 16 & 3 \\
L & 2 & 10 & 56 \\
\hline
\end{tabular}

\section{DISCUSSION}

The present study demonstrates the microgeographic scale at which genetic differentiation can occur in a moss population. The observed microgeographic differentiation is probably influenced by restricted dispersal, especially due to the limited dispersal potential for male gametes (Anderson and Lemmon, 1974; Reynolds, 1980; Wyatt, 1982). Dispersal potential for spores may be somewhat greater but still limited enough to promote genetic differentiation on a microgeographic scale. Micro- habitat differences presumably exist in the area but it is not known what role environmental heterogeneity would play in generating the observed genetic differentiation (see Longton, 1974; Shaw, Antonovics and Anderson, 1987). For example, each of the 16 sampled sites appeared to support only a small number of gametophyte genotypes. Presumably this is the result of competition for space and nutrients through vegetative reproduction among several gametophyte genotypes with the outcome being a function of genetic differences among gametophyte genotypes in response to microenvironmental conditions. Further information on these processes could be obtained by comparing the relative expansion or contraction of the area occupied by each gametophyte genotype.

As expected from previous estimates of male gamete dispersal distance (Longton, 1976; Wyatt, 1977; Reynolds, 1980; Wyatt, 1982; Longton and Schuster, 1983; Wyatt and Anderson, 1984; Wyatt, 1985), mating depends on the close proximity of male and female gametophytes. This means that extensive vegetative growth of male or female gametophytes could result in a decrease in the frequency of sporophyte production if patches consisted of only a single sex (Anderson and Lemmon, 1974; Wyatt, 1977; Longton and Schuster, 1983). A large amount of sporophyte production can be maintained in Polytrichum juniperinum, however, because male and female gametophytes appear to grow intertwined (Longton, 1976). This may be possible if there is reduced competition between the two sexes compared to competition among different gametophyte genotypes of the same sex. Support for such a process is suggested by the observation that eight of the 11 sites had male and female gametophytes growing together and composed of only one female genotype and one male genotype, based on their six-locus genotypes. A maximum of three gametophyte genotypes were found together at any one site but it is not clear if this simply represents an incomplete competitive process.

Genotypic diversity in the gametophyte stage of moss species can also be affected by the amount of asexual reproduction. For example, extensive vegetative reproduction may produce a population with limited genotypic diversity, especially if a few clones come to dominate an area (Wyatt, 1982; Longton and Schuster, 1983; Zielinski, 1986; Hofman, 1988). Vegetative reproduction in the population of Polytrichum juniperinum gametophytes sampled here has not resulted in a limited number of large clones. Areas separated by only a few 
metres consisted of different gametophyte genotypes, suggesting that clone sizes may be of the order of one or two metres in diameter. Genotypic diversity in the population conformed to that expected for a random-mating sexual population. This would seem to reflect the establishment of the population by spores produced by sexual reproduction. Any reduction in the original genotypic diversity would be through random processes, maintaining the characteristics of a sexually produced population of gametophytes in the population as a whole.

All of the sites in the population produced some sporophytes and the genetic data confirmed the occurrence of mating between adjacent male and female gametophytes. Sporophyte and viable spore production were not quantified but single sporangia for some Polytrichum species are capable of producing on the order of $10^{6}$ or more spores (Longton and Schuster, 1983). Little is known about the fate of spores or the frequency of recruitment of new gametophytes from spores for any moss species (Longton and Miles, 1982; Longton and Schuster, 1983; Mishler, 1988). Comparisons between gametophyte genotypes and sporophyte genotypes suggest that recruitment of new gametophytes from spores is relatively rare in the population studied here. This does not appear to be due to the production of inviable spores since spores collected from the population produce gametophytes under laboratory conditions (unpublished observations). A limited number of suitable microsites may be one factor preventing the germination and establishment of gametophytes from spores (Longton and Miles, 1982; Longton and Schuster, 1983). It is also possible that many of the undetected gametophyte genotypes are present in the population as only a very small number of shoots and sampling more sites would no doubt reveal additional gametophyte genotypes. There was, however, no evidence for the recruitment of new gametophyte genotypes in the small area around each sampled sporophyte where many of the spores would be expected to be dispersed (Wyatt, 1982; Longton and Schuster, 1983; Wyatt and Anderson, 1984).

Genetic factors may play a role in limiting the number of gametophyte genotypes produced by a sporophyte. Sporophytes develop for about a year after fertilisation and may have accumulated gametophytic mutations (genetic load) linked to the marker loci during the period of cell division prior to meiosis, similar to the gametophytic mutations observed in fern species (Klekowski, 1984). The marker loci may also be associated with invi- able gene combinations (synthetic lethals). Both of these genetic factors may explain observations on the production of large numbers of inviable spores for several moss species (Mogensen, 1978; Longton and Miles, 1982; Longton and Schuster, 1983). There are presently no quantitative estimates of the importance of mutational load for any bryophyte species. Some of these hypotheses could be tested by growing gametophytes derived from spores from single sporangia. It would be interesting to germinate spores from the highly heterozygous sporophytes at sites $\mathrm{J}$ and $\mathrm{L}$ to test if genetic factors can explain the absence of particular genotypic combinations at the marker loci.

Polytrichum juniperinum can be added to a growing number of studies which show that species with a predominant haploid stage are no less genetically variable than many diploid organisms (Spieth, 1975; Krzakowa and Szweykowski, 1979; Selander and Levin, 1980; Cummins and Wyatt, 1981; Daniels, 1982; Yamazaki, 1981; 1984; Vries et al., 1983; Zielinski, 1984; Wyatt, 1985; Shaw et al., 1987; Hofman, 1988; Wyatt, Odrzykoski and Stoneburner, 1989; Wyatt, Stoneburner and Odrzykoski, 1989). Low levels of genetic variation have been observed in many Hymenoptera species with the interpretation that the presence of haploid males in some way reduces genetic variation (Metcalf et al., 1975; Berkelhamer, 1983; Graur, 1985). However, a careful reassessment showed that low levels of genetic variation are not necessarily a consequence of haplodiploidy in these species (Graur, 1985). In addition, theoretical studies demonstrate that under biologically realistic conditions, selectively maintained polymorphisms are possible for haplodiploid organisms (Ewing, 1977; Curtsinger, 1980). The presence of a haploid stage in the life-cycle does not, therefore, appear to impose a limit on genetic variation.

Moss species show enough allozymic variability to be useful for studying population genetic processes in an organism with a persistent haploid stage in the life-cycle. Future studies should be able to assess the relative importance of genetical and ecological factors in determining the genotypic composition of a population. In addition, estimates of gametophytic lethals can be compared with estimates obtained for fern species to see if genetic load is also an important component of the evolutionary genetics of mosses. Further studies on bryophytes, and other species with a dominant haploid stage, will provide useful information for understanding the evolutionary factors responsible for the dominance of haploidy in some species and the dominance of diploidy in others. 
Acknowledgements This research was supported by an operating grant from NSERC and funds from Memorial University. I thank $T$. Hedderson for help in collecting the samples and valuable discussions on the biology of bryophytes. I am grateful to R. Belland, P. Hebert, T. Hedderson, J. Hutchings, B. Mayer and $\mathrm{D}$. Schneider for their comments.

\section{REFERENCES}

ANDERSON, L. E. AND LEMMON, B. E. 1974. Gene flow distances in the moss, Weissia controversa Hedw. J. Hattori Bot. Lab., 38, 67-90.

ANDERSON, L. E. AND SNIDER, J. A. 1982. Cytological and genetic barriers in mosses. J. Hattori Bot. Lab., 52, 241-254.

BELL, G. 1988. Origins of sex. J. Genet., 67, 63-66.

BERKELHAMER, R. C. 1983. Intraspecific genetic variation and haplodiploidy, eusociality, and polygyny in the Hymenoptera. Evolution, 37, 540-545.

BERNSTEIN, H., HOPF, F. A. AND MICHOD, R. E. 1987. The molecular basis of the evolution of sex. Advances in Genetics, 24, 323-370.

CUMMINS, H. AND WYATT, R. 1981. Genetic variability in natural populations of the moss Atrichum angustatum. The Bryologist, 84, 30-38.

CURTSINGER, J. W. 1980. On the opportunity for polymorphism with sex-linkage or haplodiploidy. Genetics, 96, 995-1006.

DANIELS, R. E. 1982. Isozyme variation in British populations of Sphagnum pulchrum (Braithw.) Warnst. J. Bryol., 12, $1-11$.

EWING, E. P. 1977. Selection at the haploid and diploid phases. Cyclical variation. Genetics, 87, 195-208.

GRAUR, D. 1985. Gene diversity in Hymenoptera. Evolution, 39, 190-199.

HARRIS, H. AND HOPKINSON, D. A. 1976. Handbook of Enzyme Electrophoresis in Human Genetics. North Holland, Amsterdam.

HOFMAN, A. 1988. A preliminary survey of allozyme variation in the genus Plagiothecium (Plagiotheciaceae, Bryopsida). J. Hattori Bot. Lab., 64, 143-150.

INNES, D. J., SCHWARTZ, S. S. AND HEBERT, P. D. N. 1986. Genotypic diversity and variation in mode of reproduction among populations in the Daphnia pulex group. Heredity, 57, 345-355.

KLEKOWSKI, E. J., JR. 1984. Mutational load in clonal plants. A study of two fern species. Evolution, 38, 417-426.

KRZAKOWA, M. AND SZWEYKOWSKI, J. 1979. Isozyme polymorphism in natural populations of a liverwort, Plagiochila asplenioides. Genetics, 93, 711-719.

LEWIS, W. M., JR. 1985. Nutrient scarcity as an evolutionary cause of haploidy. Amer. Nat., 125, 693-701.

LONGTON, R. E. 1974. Genecological differentiation in bryophytes. J. Hattori Bot. Lab., 38, 49-65.

LONGTON, R. E. 1976. Reproductive biology and evolutionary potential in bryophytes. J. Hattori Bot. Lab., 41, 205-223.

LONGTON, R. E. AND MILES, C. J. 1982. Studies on the reproductive biology of mosses. J. Hattori Bot. Lab., 52, 219-240.

LONGTON, R. E. AND SCHUSTER, R. M. 1983. Reproductive biology. In Schuster, R. M. (ed.) New Manual of Bryology, Hattori Botanical Laboratory, Nichinan, Japan, pp. 386462.

METCALF, R. A., MARLIN, J. C. AND WHITT, G. S. 1975. Low levels of genetic heterozygosity in Hymenoptera. Nature, 257, 792-794
MISHLER, B. D. 1988. Reproductive ecology of bryophytes. In Lovett Doust, J. and Lovett Doust, L. (eds) Plant Reproductive Ecology, Oxford University Press, New York, pp. 285306.

MOGENSEN, G. S. 1978. Spore development and germination in Cinclidium (Mniacea, Bryophyta), with special reference to spore mortality and false anisospory. Can. J. Bot., 56, 1032-1060.

NEWTON, M. E. 1984. The cytogenetics of bryophytes. In Dyer, A. F. and Duckett, J. G. (eds) The Experimental Biology of Bryophytes, Academic Press, London, pp. 65-96.

PAQUIN, C. AND ADAMS, J. 1983. Frequency of fixation of adaptation mutations is higher in evolving diploid than haploid yeast populations. Nature, 302, 495500

RAMSAY, H. P. AND BERRIE, G. K. 1982. Sex determination in bryophytes. J. Hattori Bot. Lab., 52, 255-274.

REYNOLDS, D. N. 1980. Gamete dispersal in Mnium ciliare. The Bryologist, 83, 73-77.

SELANDER, R. K. AND LEVIN, B. R. 1980. Genetic diversity and structure in Escherichia coli populations. Science, 210, 545 547

SHAW, J., ANOTNOVICS, J. AND ANDERSON, L. E. 1987. Interand intraspecific variation of mosses in tolerance to copper and zinc. Evolution, 41, 1312-1325.

SHAW, J., MEAGHER, T. R. AND HARLEY, P. 1987. Electrophoretic evidence of reproductive isolation between two varieties of the moss, Climacium americanum. Heredity, 59 , 337-343.

SNEATH, P. H. A. AND SOKAL, R. R. 1973. Numerical Taxonomy. W. H. Freeman, San Francisco.

SOKAL, R. R. AND ROHLF, F. J. 1981. Biometry, 2nd edn. W. H. Freeman, San Francisco.

SPIETH, P. T. 1975. Population genetics of allozyme variation in Neurospora intermedia. Genetics, 80, 785-805.

STODDARD, J. A. 1983. A genotypic diversity measure. $J$. Heredity, 74, 489-490.

VRIES, A. DE., ZANTEN, B. O. VAN AND DIJK, H. VAN. 1983. Genetic variability within and between populations of two species of Racopilum (Racopilaceae, Bryopsida) Lindbergia, 9, 73-80.

WYATT, R. 1977. Spatial pattern and gamete dispersal distances in Atrichum angustatum, a dioicous moss. The Bryologist, 80, 284-291.

WYATT, R. 1982. Population ecology of bryophytes. J. Hattori Bot. Lab., 52, 179-198.

WYATT, R. 1985. Species concepts in bryophytes. Inputs from population biology. The Bryologist, 88, 182-189.

WYATT, R. AND ANDERSON, L. E. 1984. Breeding systems in bryophytes. In Dyer, A. F. and Duckett, J. G. (eds) The Experimental Biology of Bryophytes, Academic Press, London, pp. 39-64.

WYATT, R., ODRZYKOSKI, I. J. AND STONEBURNER, A. 1989. High levels of genetic variation in the moss Plagiomnium ciliare. Evolution, 43, 1085-1096.

WYATT, R., ODRZYKOSKI, I. J., STONEBURNER, A., BASS, H. W. AND GALAU, G. A. 1988. Allopolyploidy in bryophytes: Multiple origins of Plagiomnium medium. Proc. Nat. Acad. Sci., 85, 5601-5604.

WYATT, R., STONEBURNER, A. AND ODRZSYKOSKI, I. J. 1989. Bryophyte isozymes: Systematic and evolutionary implications. In Soltis, D. E. and Soltis, P. S. (eds) Plant Isozymes, Dioscorides Press, Portland, Oregon (In press).

YAMAZAKI, T. 1981. Genic variabilities in natural populations of haploid plant, Conocephalum conicum. I. The amount of heterozygosity. Jpn. J. Genet., 56, 373-383. 
YAMAZAKI, T. 1984. The amount of polymorphism and genetic differentiation in natural populations of the haploid liverwort Concephalum conicum. Jpn. J. Genet., 59, 133-139.

ZANTEN, B. O. VAN AND POCS, T. 1981 Distribution and dispersal of bryophytes. Advances in Bryology, 1, 479-562.
ZIELINSKI, R. 1984. Electrophoretic evidence of cross-fertilization in the monoecious Pellia epiphylla, $\mathrm{N}=9$. J. Hattori Bot. Lab., 56, 255-262.

ZEILINSKI, R. 1986. Cross fertilization in the monoecious Pellia borealis, $n=18$, and spatial distribution of two peroxidase genotypes. Heredity, 56, 299-304. 